\title{
Audit of length of artificial feeding in adult patients with head and neck cancer in the Yorkshire Cancer Network
}

\author{
S. Cameron and L. McDermott \\ Non Surgical Oncology Dietetic Dept, Rehabilitation Dept, Level 1, St James's Institute of Clinical Oncology, \\ St James's Hospital, Beckett Street, Leeds LS9 7TF, UK
}

Between 2004 and 2005 there was an increased number of patients with head and neck cancer who were acutely admitted for artificial nutrition support at the Yorkshire Centre for Clinical Oncology (YCCO), Cookridge Hospital. These patients were subsequently discharged on home artificial nutrition support. An increased number of patients were having induction chemotherapy and/or concurrent chemo-radiotherapy. This treatment resulted in increased toxicity, causing severe acute and chronic side effects. It was necessary to undertake a regional audit to establish the changes in patients' nutritional outcomes and review service demands in the rehabilitation phase. The increased toxicity was reflected in patients requiring prolonged periods of artificial feeding ${ }^{(1)}$. The objective was to establish how long patients required artificial nutrition support and via which access route. Results were compared with national standards ${ }^{(2)}$.

A total of forty-four patients with head and neck cancer in 2004 and fifty-nine patients in 2005 were admitted acutely to YCCO for reasons including artificial nutrition support during or shortly after non-surgical treatment between 1 January 2004 and 31 December 2005. Fifty-seven patients were excluded from the audit due to incomplete or inaccessible data (data for patients who died before the audit were inaccessible). The total subject group included forty-six patients, eleven for 2004 and thirty-five for 2005 . Follow-up data were collected retrospectively across the Yorkshire Cancer Network for all patients up to 31 December 2006. In total $91 \%$ (forty-two of fortysix) of the total subject group had advanced disease (stage III or $\mathrm{IV}^{(3)}$ ) and $87 \%$ (forty of forty-six) had multimodality treatment (any combination of surgery, chemotherapy and radiotherapy).

There was an increase of $25 \%$ in the number of patients requiring artificial nutrition support between 2004 and 2005 . National standards ${ }^{(2)}$ recommend the nasogastric (NG) route for short-term feeding $(<4$ weeks) and the gastrostomy $(\mathrm{G})$-tube route for long-term feeding ( $>4$ weeks). All patients from 2004 and 2005 were fed for $>4$ weeks, the majority by an NG tube (thirty-nine of forty-six). In $20049 \%$ ( $n$ 1) of patients were artificially fed for $>365 \mathrm{~d}$ compared with $26 \%(n 9)$ in 2005 . Of the patients that were fed for $>365 \mathrm{~d}$ in 2005, four patients had a G-tube as their initial route of artificial feeding and five patients had a NG tube.

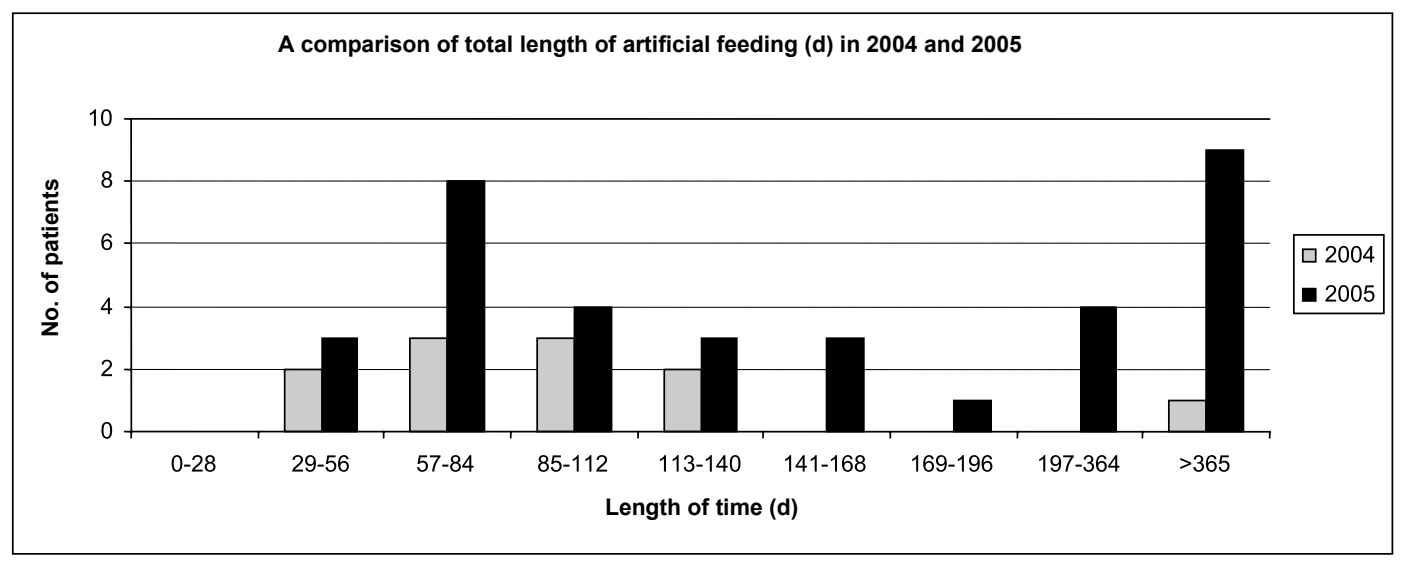

The present results show that there was an increase in the number of patients requiring artificial feeding and the length of time they were fed artificially in 2005. This finding is consistent with the increased toxicity as a result of change of treatment. The results identified the need to review practice relating to the route of artificial nutrition support for this patient group. The results also highlight the increased service pressures on the dietetic department and the need to increase resources to enable a quality dietetic service, as recommended by the National Institute for Health and Clinical Excellence ${ }^{(4)}$, to support this vulnerable patient group through treatment and rehabilitation.

1. Nguyen NP, Moltz CC, Frank C et al. (2004) Ann Oncol 15, 383-388.

2. National Institute for Health and Clinical Excellence (2006) Nutrition Support in Adults. Clinical Guideline 32. London: NICE.

3. American Joint Committee on Cancer (1997) American Joint Committee on Cancer (AJCC7) Cancer Staging Manual, 5th ed. Philadelphia, PA: Lippincott-Raven Publishers.

4. National Institute for Health and Clinical Excellence (2004) Improving Outcomes Guidance in Head and Neck Cancer. London: NICE. 